Article

\title{
Regional Economic Resilience: Resistance and Recoverability of Resource-Based Cities during Economic Crises in Northeast China
}

\author{
Juntao Tan ${ }^{1}$ (D), Kevin Lo ${ }^{2}$, Fangdao Qiu ${ }^{1}$, Wenxin Liu ${ }^{3}$, Jing $\mathrm{Li}^{3}$ and Pingyu Zhang ${ }^{3, *}$ \\ 1 School of Geography, Geomatics and Planning, Jiangsu Normal University, Xuzhou 221116, China; \\ tanjuntaocf@163.com (J.T.); qiufangdao@163.com (F.Q.) \\ 2 Department of Geography, Hong Kong Baptist University, Hong Kong 999077, China; lokevin@hkbu.edu.hk \\ 3 Northeast Institute of Geography and Agroecology, Chinese Academy of Sciences, Changchun 130002, China; \\ liuwx@iga.ac.cn (W.L.); lijingsara@iga.ac.cn (J.L.) \\ * Correspondence: zhangpy@iga.ac.cn; Tel.: +86-431-8554-2301; Fax: +86-431-8554-2298
}

Received: 29 October 2017; Accepted: 16 November 2017; Published: 30 November 2017

\begin{abstract}
This paper quantitatively analyzes the economic resilience of resource-based cities (RBCs) in Northeast China in terms of resistance and recoverability during two economic crises: the Asian financial crisis and the global financial crisis. Moreover, it analyzes the main factors that affected regional resilience. There are three main findings. First, the RBCs in general demonstrated poor resistance during both recessions, but there were variations among the different types of RBCs. Petroleum and metal cities demonstrated the most resistance, whereas coal cities performed the worst. Second, the influential factors affecting economic resilience varied across the two economic cycles, but location advantage, research and development ( $R$ and $D)$ intensity, foreign trade dependence ratio, and supporting policies had positive effects on resilience during both economic cycles, while the proportion of employed persons in resource industries had a negative effect. Industrial diversity had a weak and ambiguous effect on resilience. Third, the secondary industry was more resilient during the Asian financial crisis, but the tertiary industry was more resilient during the global financial crisis. This shift may be attributed to both the nature of the crises and the strength of the sectors at the time of the crises.
\end{abstract}

Keywords: resource-based cities; economic resilience; recessions; resistance; recoverability; Northeast China

\section{Introduction}

The word "resilience" comes from the Latin resilire, which means to rebound, and the concept was first developed in the engineering and natural sciences to explain the capacity of systems to persevere when subjected to external shock disturbances [1-3]. The concept of resilience today is applicable to a variety of disciplines with different meanings, functions, and relevance [4-6]. From the evolutionary perspective of economic geography, the concept of adaptive resilience has been developed to represent the ability of regional or urban economic systems to undergo reorganization to facilitate recovery after a shock and to reset their growth path $[1,7,8]$. Simmie and Martin defined regional economic resilience in terms of "adaptive ability", referring to the differential ability of a region or local firm to adapt to changes and shocks under competitive market, technological, policy conditions [9].

The increasing frequency of recession shocks following the deregulation of financial and economic systems in the 1980s has had great impacts on regional growth [10]. Different regions respond in different ways to recessionary shocks and the subsequent recovery period, which has triggered research on the subject of regional economic resilience, including conceptual debates $[4,11,12]$ and 
empirical studies [10,13-15]. In general, disturbances, such as external shocks have been used as the basis for measuring regional resilience. Pendall et al. claimed that the regions faced two main categories of disturbance: shocks and slow burns [16]. Most existing studies have regarded the recessionary shocks as a disturbance to regional growth trajectories $[9,10,17]$, and explored the various responses of regions to recessionary shocks. Cellini and Torrisi studied regional resilience in Italy over the 1890-2009 period [18]; Simmie and Martin focused on the evolutionary adaptive cycle model, and two cities, Cambridge and Swansea, were used to explore the model [9]; Davies examined how and why economic resilience varies among European countries [19]. Recently, an increasing number of empirical studies have examined the economic resilience characteristics of different regions, such as Australia, Canada, and Turkey, using variables such as GDP, total number of employment, and employment rates [10,20-22]. However, research on regional resilience in China is still very limited. Tan et al. developed a conceptual model and an indicator system for measuring economic resilience of resource-based cities based on the theory of evolutionary resilience [23]. Hu and Hassink developed a novel conceptual framework of adaptation-adaptability and used it to explain the uneven resilience between Zaozhuang and Fuxin in China [24]. They found that Zaozhuang was able to develop strong resilience through endogenous purposive adaptation, whereas in Fuxin, the overwhelming influence of top-down governance contributed to a disconnect between adaptation and adaptability. The root of the problem of top-down adaptation governance is that the central government often aims to achieve national priorities in the name of local development [25].

Regional economic resilience is determined by a complex array of economic, institutional, political, and historical factors [13]. Some empirical studies have identified various factors that shape economic resilience. A diversified industrial mix, a skilled and innovative workforce, modern productive infrastructure, supportive financial systems, liberal market conditions, knowledge networks between universities and local economies, and proactive government strategies have all been suggested to enhance resilience $[4,7,14,15,26-28]$. These studies typically establish the level of resilience to recessionary shocks and then explore the determining factors. However, they usually focus on a national scale rather than the regional or local scale. Consequently, the local characteristics of regional economic systems have not been sufficiently analyzed. Furthermore, empirical studies on the attributes of regional resilience usually focused on certain types of factors, and lack comprehensive analysis.

RBCs are cities whose economies depend primarily on exploiting and processing natural resources [29]. The economic resilience of RBCs is the capacity of RBCs to withstand or recover from economic, social, and environmental shocks to its developmental growth path, or to transit to a new sustainable growth path characterized by a more productive use of physical, human, and natural resources. We focus on RBCs because they are highly susceptible to external shocks associated with resource depletion and resource price fluctuations. Furthermore, a specialized industrial structure and weak regional competitiveness can decrease a city's ability to adjust and adapt to shocks, whereas weak levels of innovation and a lack of urgency to transition further decrease their ability to create new growth paths. Therefore, it is reasonable to believe that RBCs' economic resilience is relatively poor and, thus, enhancing RBCs' resilience is a pressing policy challenge.

The field of regional resilience has been enriched by an interesting mix of qualitative and quantitative studies [30,31]. Qualitative studies tend to focus on the processes through which key actors build resilience or respond to external shocks, whereas quantitative work provides statistical analysis on regions that are able to recover their growth paths [32]. Because this study aims to comparatively investigate 19 RBCs in Northeast China, it adopts a quantitative approach. More specifically, to explore how different RBCs react to economic crises, and why some cities are better able to overcome the negative effects of recessionary shocks, this study measures the economic resilience of RBCs in Northeast China in terms of resistance and recoverability during two recent economic recessions, and then analyzes the main factors that contributed to regional resilience.

The remainder of the paper proceeds as follows: Section 2 describes the study area; Section 3 presents the regional resilience characteristics of $19 \mathrm{RBCs}$ during the last two major recessionary 
periods; Section 4 analyzes the determinants of regional resilience, followed by a discussion of the key conclusions in Section 5.

\section{Study Area}

Northeast China, as a region, officially includes the provinces of Liaoning, Jilin, and Heilongjiang, and the eastern part of Inner Mongolia. Liaoning, Jilin, and Heilongjiang are commonly considered the core of Northeast China. We focused on the RBCs in this region because they are the centers of economic activities. RBCs in Northeast China were mainly developed during the planned economy era with a specialized economic structure to produce energy, mineral, or timber resources. With resource depletion, the economic systems of these RBCs have come under tremendous pressure. There are 21 RBCs in the study area: six in Liaoning, six in Jilin, and nine in Heilongjiang (Figure 1). We excluded Daxinganling in Heilongjiang and Yanbian Korean Autonomous Prefecture in Jilin due to data limitations. The remaining 19 RBCs accounted for $36.7 \%$ of the total GDP in the Northeast, which grew at an average rate of $6.4 \%$ in 2013. This rate was below the average for Northeast China, $8.4 \%$. In fact, the economy of several RBCs shrank: the output in Qitaihe, Hegang, Jixi, and Shuangyashan declined by $19.38 \%, 10.67 \%, 1.96 \%$, and $1.83 \%$, respectively. These RBCs hold key national natural resource reserves, especially oil, and iron: oil and iron ore reserves accounted for $24.36 \%$ and $30.4 \%$, respectively, of the national total in 2013.

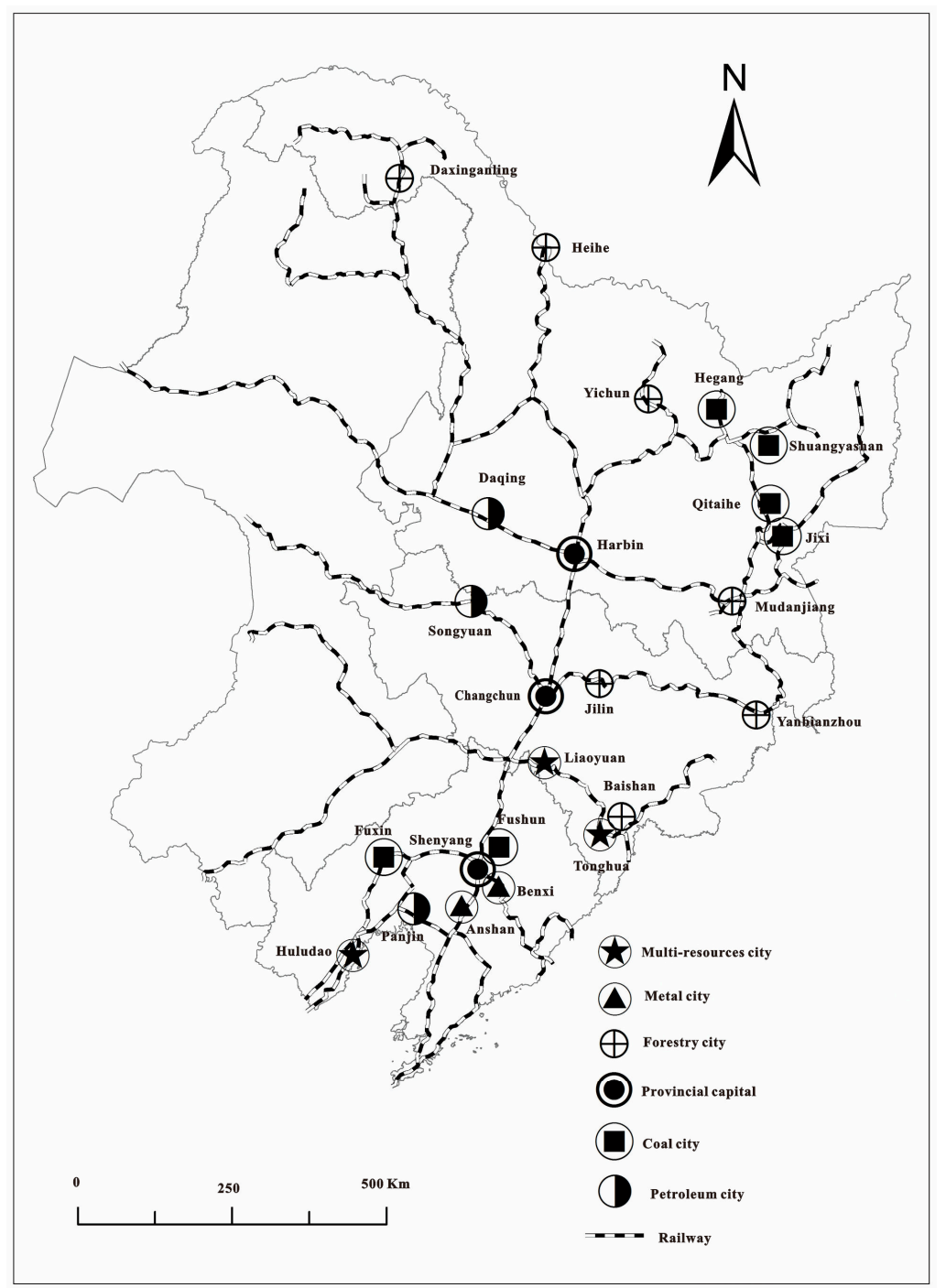

Figure 1. Spatial distribution of the main RBCs in Northeast China. 


\section{The Resilience of RBCs to Major Recessions}

\subsection{Major Recessionary Shocks}

China has experienced four significant economic downturns in the post-1978 reform period: from 1979 to 1981, from 1987 to 1990, from 1997 to 1999, and from 2008 until now. The first two recessions were caused by austerity measures to prevent an overheated economy [33], while the latter two recessions were the result of international market conditions (the Asian financial crisis and the global financial crisis). Given that the first two recessions were mainly caused by domestic macro-economic policy, we focused our study on the two most recent recessions.

Previous studies usually use either employment or economic output (e.g., gross domestic product, GDP) data to measure economic resilience [13,22]. Employment has continually grown in China and is less affected by economic recession because of the dominate position of state-owned enterprises who offer secure employment [34]. Furthermore, in most cities, employment data is incomplete because only the urban employment data is available. Therefore, this study uses output data (GDP) to measure economic resilience. While it is true that using GDP may also have some problems in accuracy and reliability [35], GDP is still the most authoritative and commonly used data in China. Overall, the GDP growth rate of the three provinces in Northeast China was similar to that of China, as they all declined from 1997 to 1999; recovered in the following years; peaked in 2007; declined again in 2008, recovered briefly in 2010; and declined again to the present time (Figure 2).

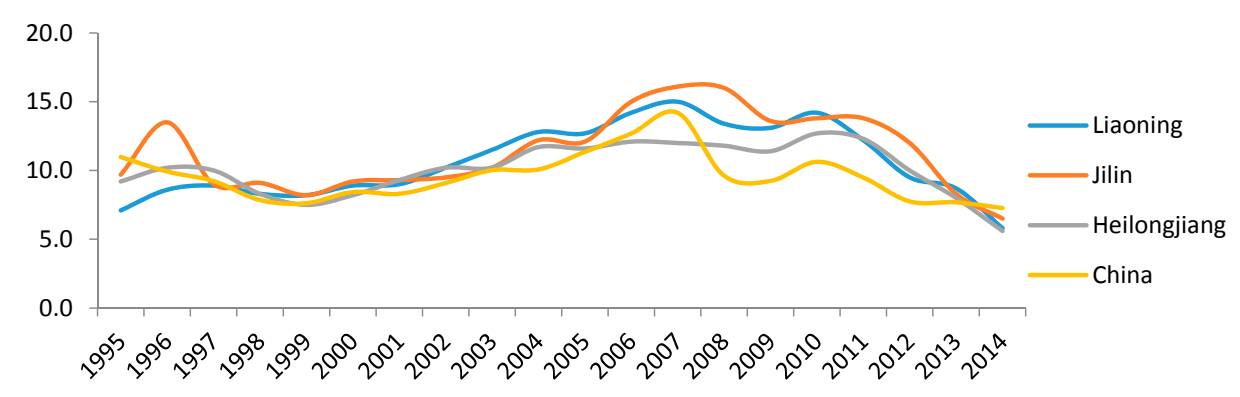

Figure 2. GDP growth rate in Northeast China and the whole country, 1995-2014.

Figures 3-5 show the GDP growth rate since 1995 of the RBCs in Liaoning, Jilin, and Heilongjiang, respectively. We can see that the GDP growth rate in the RBCs was similar to that of China, bottoming out in around 1999, peaking in around 2007, fluctuating between 2008 and 2010, and since demonstrating a continuous downward trend. We could also see that the RBCs generally experienced recessions between the major recessionary periods. Taking Fuxin as an example, it shows seven peaks and experienced more than two recessions since 1995. Fuxin experienced continual economic growth after 2001, reaching 20 percent around 2003, which was related to the national economic recovery cycle. However, in 2001, Fuxin began a self-initiated economic transition as an experimental resource-based city, which helped sustain the high growth rate of the city.

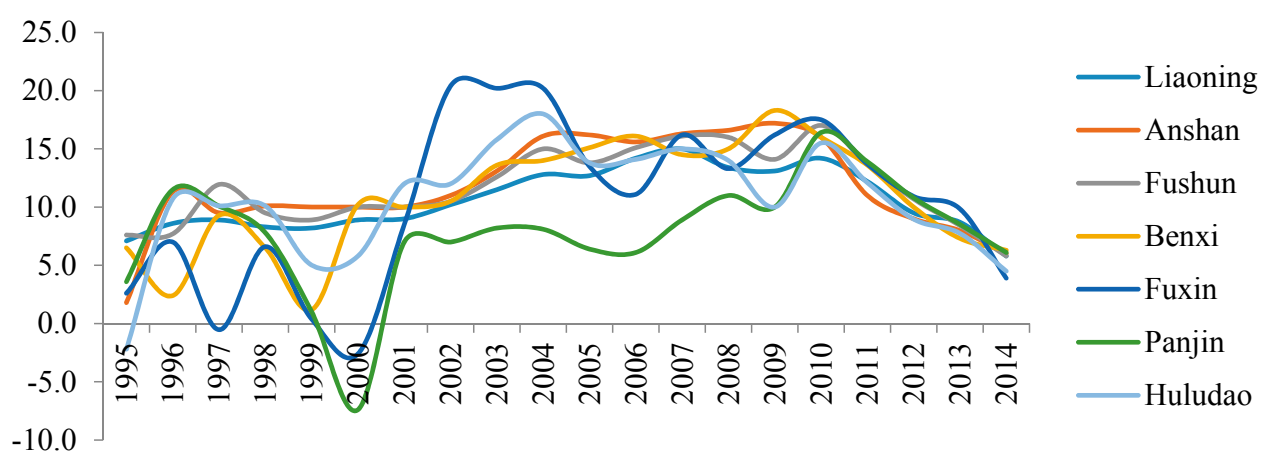

Figure 3. GDP growth rate of RBCs in Liaoning Province, 1995-2014. 


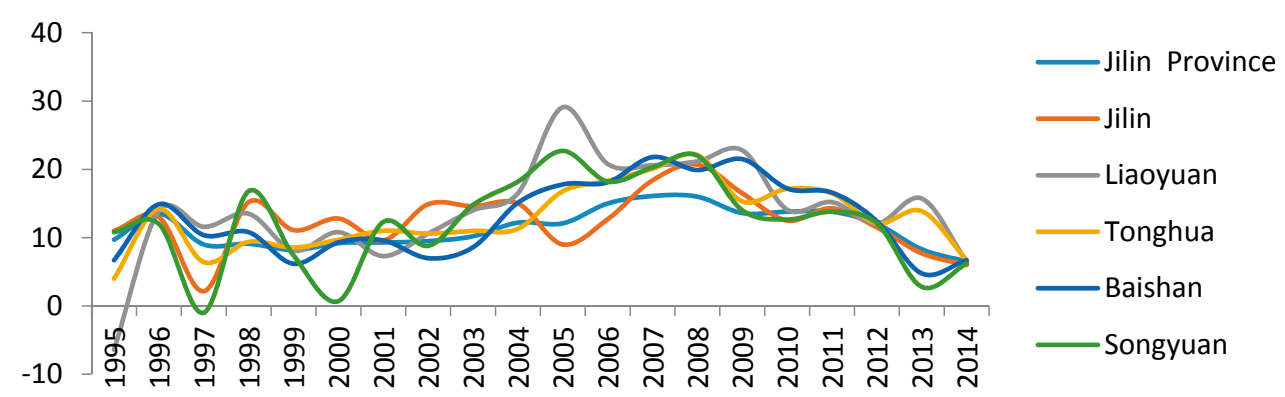

Figure 4. GDP growth rate of RBCs in Jilin Province, 1995-2014.

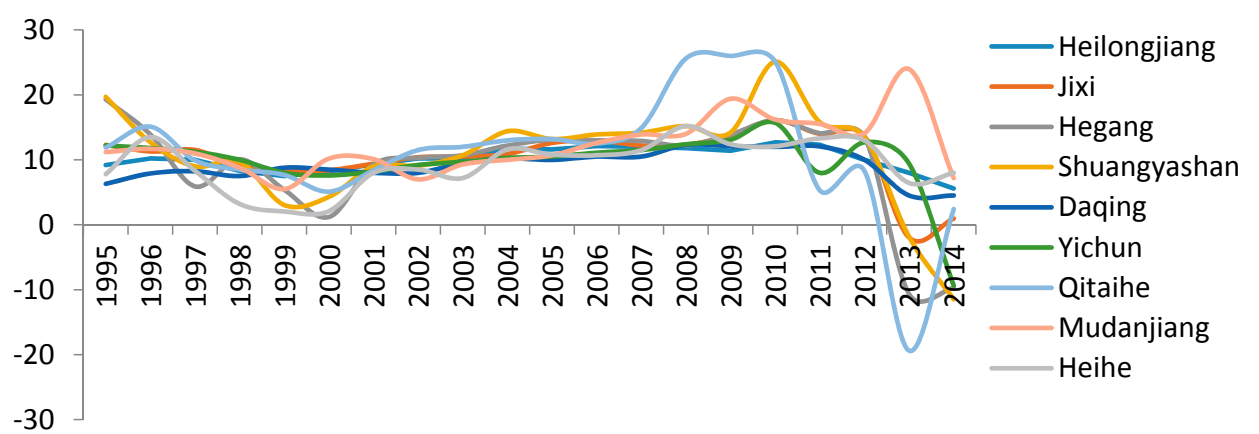

Figure 5. GDP growth rate of RBCs in Heilongjiang Province, 1995-2014.

\subsection{Measuring Resistance and Recoverability}

Martin identified four interrelated dimensions of economic resilience, including resistance (the degree of sensitivity or the initial impact of shocks), recoverability (the speed and degree of recovery from shocks), re-orientation (the extent of reorientation and adaptability of a regional economy in response to the shock), and renewal (the extent to which a regional economy renews its pre-shock growth path or hysteretic shift to a new path) [7]. This study focuses on measuring two of the four dimensions of resilience, namely resistance and recoverability. Our approach here is not to assume an autonomous path or returning to the pre-shock growth path, but to focus on how regions react to recessions from peak to trough, as well as recovering from trough to peak. There were several different methods to measure resistance and recoverability. Martin used the sensitivity index and average growth rate to measure regional resistance and recoverability that are affected by a common (national) recession [7]. The trajectory of the national economy as a whole is taken as the expected change of regions. In other words, the expected change of economy in region $r$ during a recession or recovery, say of the duration of k periods, would be given as:

$$
\left(\Delta E_{r}^{t+k}\right)^{e}=\sum_{i} E_{i r}^{t}\left(1+g_{N}^{t+k}\right)
$$

where $g_{N}^{t+k}$ is the rate of contraction or expansion of national output, and $E_{i r}^{t}$ is the output growth rate in industry $i$ in region $r$ at starting time $t$, the base years. Then, the RBCs' resistance and recoverability can be expressed as:

$$
\begin{aligned}
& \text { Resis }_{r}=\frac{\left(\Delta E_{r}^{\text {Contraction }}\right)-\left(\Delta E_{r}^{\text {Contraction }}\right)^{\text {expected }}}{\left|\left(\Delta E_{r}^{\text {Contraction }}\right)^{\text {expected }}\right|} \\
& \operatorname{Recov}_{r}=\frac{\left(\Delta E_{r}^{\text {Recovery }}\right)-\left(\Delta E_{r}^{\text {Recovery }}\right)^{\text {expected }}}{\left|\left(\Delta E_{r}^{\text {Recovery }}\right)^{\text {expected }}\right|}
\end{aligned}
$$


A positive value of Resis $_{r}$ indicates that the region's economy contracted more slowly than the national economy during recession and, therefore, was more resistant to recession. A positive value of $\operatorname{Recov}_{r}$ indicates that the region's economy grew faster than the national average during the recovery period and, therefore, demonstrated more recoverability. The resistance and recoverability of the RBCs in Northeast China, calculated using Equations (2) and (3), for the last two recession-recovery cycles are shown in Figures 6 and 7.

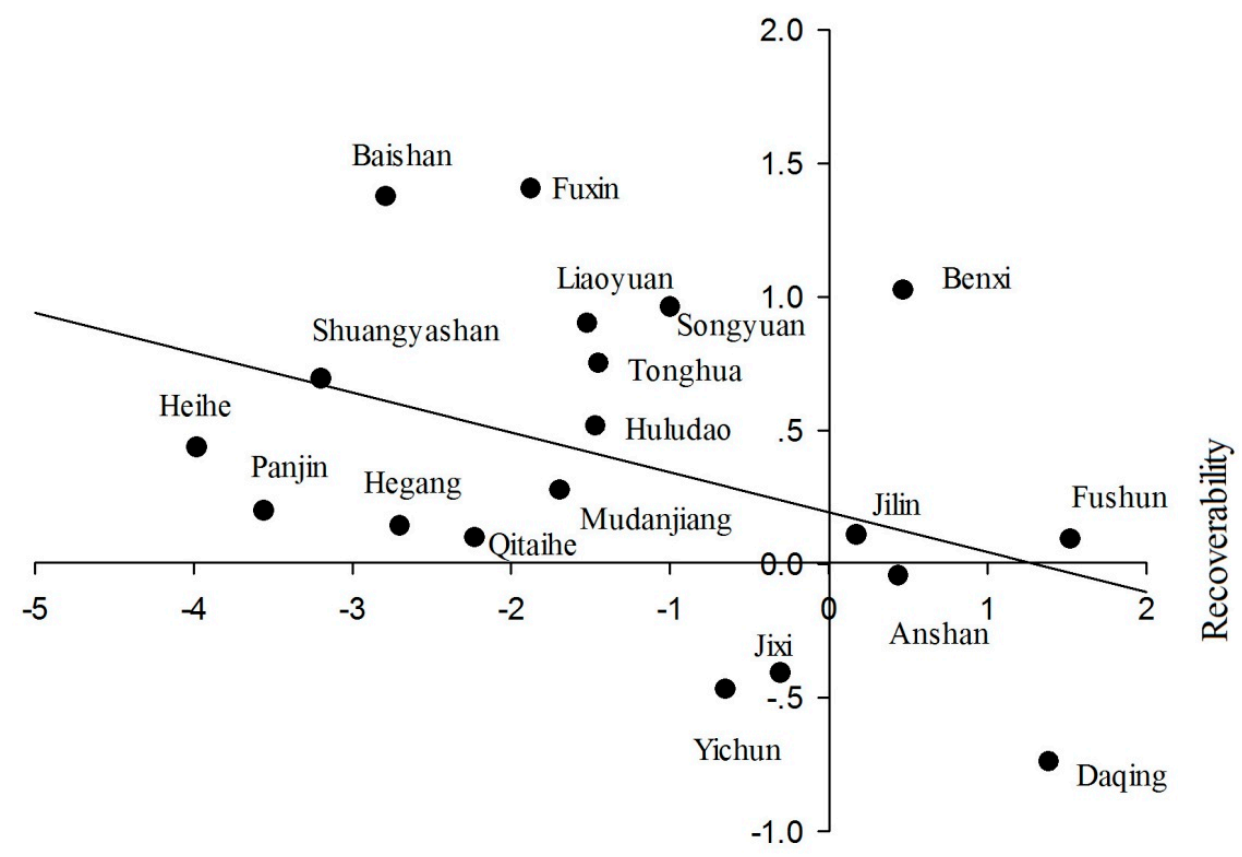

Resistance

Figure 6. Resistance and recoverability of the RBCs for the economic cycle (1996-2007).

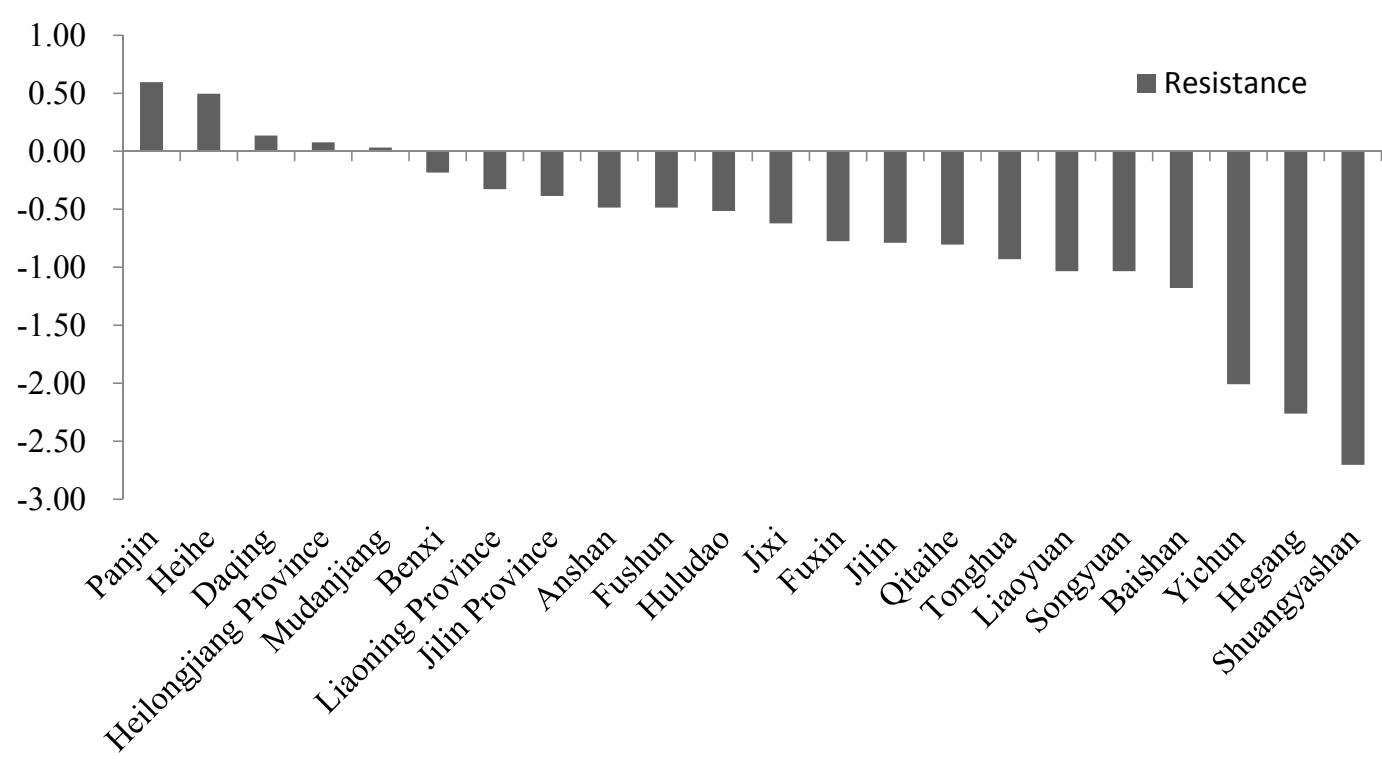

Figure 7. Resistance of RBCs in Northeast China after 2007.

Analyzing the resistance and recoverability in the first recession-recovery cycle (1996-2007), we could draw the following conclusions. First, resistance and recoverability had a strong negative correlation (the correlation coefficient is -0.401), indicating that the cities with high resistance tended 
to be weak in recoverability, whereas cities that suffered from deep recessions typically rebounded at a faster pace. Second, only Fushun, Daqing, Benxi, and another five cities demonstrated a resistance higher than zero, indicating the resistance to recession among the RBCs was generally weak. On the contrary, most cities' recoverability values were higher than zero, with only Daqing, Yichun, Jixi, and Anshan having recoverability values lower than zero, which means that the recoverability of the RBCs was higher than the national average. Third, based on the values of resistance and recoverability, 19 RBCs could be divided into four categories. The majority of the cities, including Baishan and another 12 cities, belonged to the low resistance-high recoverability group; Fushun, Jilin, and Benxi belonged to the high resistance-high recoverability group; Anshan and Daqing belonged to the high resistance-low recoverability group; and Jixi and Yichun belonged to the low resistance-low recoverability group. Fuxin, chosen as a pilot economic transition resource-based city in 2001, had the highest economic recoverability in the first recession-recovery cycle. This seems be related to the fact that Fuxin had changed the coal-based mono-structure by embarking on several new industrial paths, such as agriculture/food and wind power [24,25].

The second economic cycle (2007-2014) was characterized by the external shock associated with the 2008 global financial crisis. China's national economy experienced a brief recovery phase in 2010; but after that, the rate of economic growth continued to trend downwards, and the RBCs in Northeast China generally experienced a similar trend. Analyzing the resistance in this second cycle, we could draw the following conclusions. First, the overall level of resistance among the three northeast provinces remained low in the second cycle, with only Heilongjiang Province recording a higher than national average resilience level. In fact, the GDP growth rate in Liaoning, Jilin, and Heilongjiang was only $5.8 \%, 6.5 \%$, and $5.6 \%$ in 2014 , putting them firmly in the last five provinces nationally. Second, resistance of the RBCs was lower than the provincial averages, with only Panjin, Heihe, Daqing, and Mudanjiang having resistance scores greater than zero, and 15 RBCs had resistance scores lower than the national average. This suggests that the economies of RBCs with the exploitation and primary processing of natural resources as the leading industry are inherently vulnerable. Due to the global financial crisis, international demand for China's natural resources fell significantly, and as the government began to place more emphasis on resource efficiency and environmental protection, the demand for coal, oil, and steel declined. Consequently, the production inventory was increased; prices fell, profits declined, and all these factors contributed to the decline of RBCs' economies. In this economic cycle, Fuxin has low economic resistance, and this is related to the fact that Fuxin had short-term new path creation and was soon locked into the old path continuity [24].

Based on the types of resources on which their economies are based, the RBCs were divided into five types (multi-resource, petroleum, metal, coal, and forestry cities), and the mean values of resistance and recoverability for each type were calculated (Table 1). We found that only the metal cities' resistance was higher than zero, and other types were all lower than the national average in 1996-1999; forestry cities were the lowest. The recoverability of all types of cities was higher than zero during the recovery period (1999-2007), and the multi-resource cities had the highest values. In the recession period after 2008, the resistance of all types of cities was lower than the national average. The petroleum cities had the highest resistance, followed by metal cities and forestry cities; and coal cities were lowest. The resistance of petroleum cities was the highest due to their robust economies and the abundant oil reserves. Metal-based cities exhibited relatively high resistance due to the adjustment of their industrial structures. For example, Benxi accelerated the development of its biomedical industry; Anshan developed fine steel, deeply processed steel, and new materials for the magnesite industry. The economic recession of coal cities was the worst. This was primarily because the price of coal products had been low for a long period of time and coal resources were being exhausted. The coal cities of Qitaihe, Shuangyashan, Hegang, and Fuxin were all categorized as "recessionary resource-based cities", whose resources were being exhausted. 
Table 1. Average values of resistance and recoverability for each type of RBC.

\begin{tabular}{cccc}
\hline & Recession (1996-1999) & Recovery (1999-2007) & Recession (2007-2014) \\
\hline Multi-resource & -1.48 & 0.72 & -0.83 \\
Petroleum & -1.06 & 0.14 & -0.10 \\
Metal & 0.45 & 0.49 & -0.33 \\
Coal & -1.46 & 0.34 & -1.28 \\
Forestry & -1.79 & 0.35 & -0.69 \\
\hline
\end{tabular}

The resistance and recoverability of different sectors of the industries over the last two economic cycles in RBCs were analyzed. Since the primary industry was primarily influenced by climate rather than economic recessions, we focused on analyzing the secondary and tertiary industries (Table 2). Turning to the first economic cycle, we could identify the following phenomena: First, the tertiary industry in general had a much lower level of resistance than the secondary industry. The tertiary industry in most cities had negative resistance, with only Fushun, Huludao, Jilin, and another six cities having tertiary industries with a resistance higher than zero. On the other hand, most RBCs' secondary sectors had a positive resistance score, with only Liaoyuan, Panjin and another five cities having a negative resistance score. Second, the recoverability of the secondary industry was higher than the tertiary industry. Only Qitaihe, Panjin, and Yichun's secondary industry recoverability was lower than the national average; while the general recoverability of tertiary industries was relatively low, with only seven cities having scores higher than the national average. Overall, it can be concluded that the secondary industry was stronger than the tertiary industry in terms of economic resistance during the first economic cycle.

The situation was different in the second economic cycle. The tertiary industry resistance was, in general, higher than the secondary industry: the mean value of secondary and tertiary industry resistance of RBCs were -1.41 and -0.36 , respectively. The resistance of Anshan, Benxi, Panjin, and another five cities' tertiary industries was higher than zero, and only Panjin and Yichun had secondary industries with a resistance higher than zero.

Table 2. The resistance and recoverability of secondary and tertiary industries.

\begin{tabular}{ccccccc}
\hline & \multicolumn{2}{c}{ Resistance (1997-1999) } & \multicolumn{2}{c}{ Recoverability (1999-2007) } & \multicolumn{2}{c}{ Resistance (2007-2014) } \\
\hline & $\begin{array}{c}\text { Secondary } \\
\text { Industry }\end{array}$ & $\begin{array}{c}\text { Tertiary } \\
\text { Industry }\end{array}$ & $\begin{array}{c}\text { Secondary } \\
\text { Industry }\end{array}$ & $\begin{array}{c}\text { Tertiary } \\
\text { Industry }\end{array}$ & $\begin{array}{c}\text { Secondary } \\
\text { Industry }\end{array}$ & $\begin{array}{c}\text { Tertiary } \\
\text { Industry }\end{array}$ \\
\hline Anshan & 1.15 & -0.6 & 2.04 & -0.58 & -0.74 & 0.22 \\
Fushun & 0.82 & 3.5 & 1.15 & -0.39 & -0.63 & 0 \\
Benxi & 1.94 & -2.8 & 3.46 & 0.23 & -0.17 & 0.05 \\
Fuxin & 2.04 & -2.8 & 0.45 & 0.43 & -0.83 & -0.11 \\
Panjin & -0.27 & -0.6 & -1.05 & -0.74 & 0.7 & 0.22 \\
Huludao & -1.03 & 3.8 & 0.59 & -0.61 & -0.5 & -0.16 \\
Jilin & 1.44 & 0.32 & 0.81 & 0.53 & -0.92 & -0.62 \\
Liaoyuan & -6.23 & -4.43 & 0.27 & 0.74 & -1.7 & -0.36 \\
Tonghua & 1.49 & 3.92 & 0.53 & 0.42 & -1.32 & -0.53 \\
Baishan & 0.99 & -10.9 & 0.4 & 1.62 & -1.66 & -0.68 \\
Songyuan & 2.05 & 13.09 & 1.1 & -0.03 & -1.58 & -1.42 \\
Jixi & 0.16 & -3.7 & 0.35 & -0.71 & -2.12 & 0.31 \\
Hegang & -0.87 & -3.6 & 1.12 & -0.37 & -1.47 & -0.36 \\
Shuangyashan & -1.48 & -4.3 & 0.43 & -0.37 & -3.56 & -0.86 \\
Daqing & 1 & 1.5 & 0.49 & -1.12 & -5.42 & -1.19 \\
Yichun & 0.44 & -10.5 & -0.65 & 0.86 & 0.18 & -0.09 \\
Qitaihe & -1 & -5.3 & -5.2 & -0.84 & -3.59 & -1.29 \\
Mudanjiang & 1 & -2.6 & 11.59 & -0.69 & -1.13 & -0.54 \\
Heihe & -1.91 & 3.5 & 0.44 & -1.13 & -0.4 & 0.49
\end{tabular}




\section{Determinants of the Resilience of RBCs in Northeast China}

\subsection{Determinants of Regional Resilience}

It is important to analyze how regions respond to shocks, as well as explain the causes of these responses, bearing in mind the causes may be multiple and interconnected [13]. Martin et al. categorize the various types of determinants into compositional, collective, and contextual factors [36]. Moreover, regional resilience can be shaped by four main economic interacting subsystems: structural and business subsystems, labor market subsystems, financial subsystems, and governance subsystems. Eraydin measured the resilience of Turkish regions and explored its determinants in terms of vulnerability, resources, adaptive capacity, and supportive policies [10]. Martin et al. argued that regionally-specific factors can predict the ability of a region to resist and respond to economic shocks [13]. Lagravinese suggested that regions with a higher share of public and service industries are more resistant to economic shocks [37], while Di Caro found that certain types of manufacturing activities could help to explain the high resilience of some regions during recessions and recoveries [14]. Pike examined the role of local institutions and governance in shaping regional resilience [38]. The role of other factors, such as location and the presence of high growth firms have been examined as well $[39,40]$.

Drawing on these insights, this study selected 14 indicators, including urban development, industrial structure, labour conditions, financial arrangement, and governance aspects. For urban development aspect, we selected location advantage, resource availability, urban scale, and economic basis. Location advantage is determined based on the distance between the city and the provincial capital. For resource availability, the RBCs were official classified into four types-growing, mature, recessionary, and recovered-based on the support capabilities of resources in the National Resource Sustainable Urban Development Plan (2013-2020), and we assigned a value of 4, 3, 2, and 1 to the four types of cities. Economic basis is represented by the GDP growth rate at the beginning of a recession or recovery. Industrial specialization, proportion of tertiary industry, $\mathrm{R}$ and $\mathrm{D}$ intensity, and the proportion of employed persons in resource industries were used to represent industrial structure. Industrial specialization was calculated by using an entropy index based on regional sector employment data.

In the period of 2008-2014, the cities were given different values based on different supporting policies, as shown in Table 3. Since the policies supporting RBCs were implemented from 2003 onwards, the study did not consider the supporting policies in the period of 1997-1999. Indicators, except urban development, tax revenue, investment in fixed assets, and supporting policies, took the average value for the respective period of recession or recovery.

Table 3. Assigned values of policy support for RBCs in Northeast China.

\begin{tabular}{clc}
\hline Urban & \multicolumn{1}{c}{ Supporting Policies } & Assigned Value \\
\hline $\begin{array}{c}\text { Anshan, Benxi, Songyuan, } \\
\text { Jixi, Mudanjiang }\end{array}$ & Policy support for general resource-based cities & 1 \\
\hline Hegang, Shuangyashan & Policy support for third batch of resource-exhausted cities & 2 \\
\hline $\begin{array}{c}\text { Tonghua } \\
\text { (Erdaojiang district) }\end{array}$ & Policy support for third batch of resource-exhausted districts & 2 \\
\hline Fushun, Qitaihe & Policy support for second batch of resource-exhausted cities & 3 \\
\hline $\begin{array}{c}\text { Jilin (Shulan), } \\
\text { Heihe (Wudalianchi) }\end{array}$ & Policy support for second batch of resource-exhausted counties & 3 \\
\hline $\begin{array}{c}\text { Huludao } \\
\text { (Nanpiao district) }\end{array}$ & Policy support for second batch of resource-exhausted districts & 3 \\
\hline Daqing & $\begin{array}{l}\text { Policy support for experimental resource-based cities for } \\
\text { economic transition }\end{array}$ & 4 \\
\hline $\begin{array}{c}\text { Fuxin, Panjin, Liaoyuan, } \\
\text { Baishan, Yichun }\end{array}$ & $\begin{array}{l}\text { Policy support for experimental resource-based cities for } \\
\text { economic transition and first batch of resource-exhausted cities }\end{array}$ & 4 \\
\hline
\end{tabular}




\subsection{Geographical Detector}

We developed a geographical detector model to analyze the factors that influence regional resilience. Geographic detectors were initially applied to the study of endemic diseases and the relevant geographic risk factors [41], and they have since been adapted to the study of urbanization, economic growth, and other socioeconomic phenomena. In contrast to conventional statistical methods, geographical detectors identify correlations between variables by looking at their spatial distribution [42]. If certain factors and a change in geographical objects have a significant spatial correlation, this indicates that these factors have decisive significance for the occurrence and development of geographical objects [41,43].

Assuming the resistance or recoverability of RBCs is $U$, and the number of RBCs is $n$, the influential factor for resilience is $D=\left\{D_{i}\right\}$ ( $i$ denoting the number of classifications), and the total number is $m$. Overlaying layers $U$ and $D$, and the dispersion variance of $U$ over the sub-regions of the influential factors, $D_{i}$ is denoted as $\sigma^{2} U_{D, i}(i=1,2, \ldots \mathrm{m})$; thus, the power of the determinant $D=\left\{D_{i}\right\}$ to the economic resistance or recoverability $U$ is specified as:

$$
P_{D, U}=1-\frac{1}{n \sigma^{2} u} \sum_{i=1}^{m}\left(n_{D, i} \cdot \sigma^{2} u_{D, i}\right)
$$

where $n_{D, i}$ denotes the number of RBCs in sub-regions with the influential factors $D_{i}$, and $\sigma^{2} u$ denotes the dispersion variance of $U$ in the entire region. $P_{D, U} \in[0,1]$. When $P_{D, U}=0$, this shows that the resilience of RBCs is randomly distributed. The larger $P_{D, U}$ is, the greater the impact of the factors on resilience.

We categorized the continuous factors using the Jenks method in ArcGIS because categorical data are better than continuous data for the processing of geographical detectors. We calculated the power of the influential factors over the cities' resilience $\left(P_{D, G}\right)$ using the factor detector and analyzed the effects of the different influential factors on the resilience of the RBCs (Table 4). The factors that affect resilience varied across the two economic cycles. During the first recessions, urban scale (0.724), location (0.544), fiscal revenue (0.511), and proportion of employees for scientific research and technical services (0.441) had a strong positive impact on resilience, whereas the proportion of tertiary industry $(-0.296)$ had the strongest negative impact. Cities with non-agricultural populations of more than one million in their urban areas had better resistance than smaller cities. The mean value of resistance for cities with non-agricultural populations of less than 200,000, 200,000-500,000, 500,000-1,000,000, and more than $1,000,000$ were $-3.98,-2.03,-1.47$, and 0.88 , respectively. The proportion of employees for scientific research and technical services $\left(X_{10}\right)$, economic basis $\left(X_{4}\right)$, and urban scale $\left(X_{3}\right)$ had a significant negative effect on recoverability. This is primarily due to recoverability having a high negative correlation with resistance.

During the second economic cycle, resource availability (0.502) and policy support (0.497) had the strongest positive impact on resilience, whereas unemployment $(-0.499)$ had the strongest negative impact. The mean value of resistance in growing, mature, declining, and regenerative cities were $-1.03,-0.16,-1.41$, and -0.33 , respectively. The mature cities are ranked best in resistance, primarily because resource exploitation in these cities was stable. Moreover, these cities have abundant resources which, to a certain extent, protect them from economic crises. The regenerative cities are ranked second because these cities have already moved on from a state of resource dependency by successfully cultivating alternative industries with high growth rates. The declining cities performed worst. The natural resources in these cities were exhausted, and alternative industries have failed to emerge.

Supporting policies were also shown to have a great impact on resistance, which indicates that national policies and financial support are integral to improving resilience. Panjin and Daing, which are experimental resource cities in economic transition, and Heihe, which is a resource-exhausted city designated for policy support, all performed well in terms of resistance. The registered unemployment 
rate was shown to have a negative effect on resistance, which indicates that good labor conditions contribute to building resistance.

In addition to these differences, we could also find that location, $\mathrm{R}$ and $\mathrm{D}$ intensity, and foreign trade dependence ratio always had a positive effect on resilience, while the proportion of employed persons in resource industries $\left(\mathrm{X}_{8}\right)$ always had a negative effect.

Table 4. Factors determining resistance and recoverability.

\begin{tabular}{|c|c|c|c|c|}
\hline & \multirow[b]{2}{*}{ Factors } & \multicolumn{3}{|c|}{$P_{D, U}$} \\
\hline & & $\begin{array}{l}\text { Resistance } \\
\text { (1997-1999) }\end{array}$ & $\begin{array}{l}\text { Recoverability } \\
\text { (1999-2008) }\end{array}$ & $\begin{array}{r}\text { Resistance } \\
(2008-2014)\end{array}$ \\
\hline \multirow{4}{*}{$\begin{array}{l}\text { Urban } \\
\text { Development }\end{array}$} & Location $\left(\mathrm{X}_{1}\right)$ & 0.544 & 0.279 & 0.175 \\
\hline & Resource availability $\left(\mathrm{X}_{2}\right)$ & 0.132 & -0.191 & 0.502 \\
\hline & Urban scale $\left(X_{3}\right)$ & 0.724 & -0.330 & 0.323 \\
\hline & Economic basis $\left(\mathrm{X}_{4}\right)$ & 0.178 & -0.357 & -0.295 \\
\hline \multirow{4}{*}{$\begin{array}{l}\text { Industrial } \\
\text { Structure }\end{array}$} & Industrial specialization $\left(X_{5}\right)$ & -0.219 & 0.205 & 0.159 \\
\hline & Proportion of tertiary industry $\left(\mathrm{X}_{6}\right)$ & -0.296 & -0.350 & 0.307 \\
\hline & R \& D intensity $\left(X_{7}\right)$ & 0.171 & 0.295 & 0.249 \\
\hline & $\begin{array}{l}\text { Proportion of employed persons in } \\
\text { resource industries }\left(\mathrm{X}_{8}\right)\end{array}$ & -0.182 & -0.132 & -0.102 \\
\hline \multirow{2}{*}{$\begin{array}{l}\text { Labor } \\
\text { Condition }\end{array}$} & Unemployment rate $\left(X_{9}\right)$ & -0.249 & 0.242 & -0.499 \\
\hline & $\begin{array}{l}\text { Proportion of employee for scientific } \\
\text { research and technical services }\left(X_{10}\right)\end{array}$ & 0.441 & -0.460 & 0.212 \\
\hline \multirow{2}{*}{$\begin{array}{c}\text { Financial } \\
\text { Arrangement }\end{array}$} & Foreign trade dependence ratio $\left(\mathrm{X}_{11}\right)$ & 0.151 & 0.119 & 0.312 \\
\hline & $\begin{array}{l}\text { Cumulative per capita fiscal } \\
\text { revenue }\left(\mathrm{X}_{12}\right)\end{array}$ & 0.511 & -0.190 & 0.299 \\
\hline \multirow[b]{2}{*}{ Governance } & Policy support $\left(\mathrm{X}_{13}\right)$ & - & 0.057 & 0.497 \\
\hline & $\begin{array}{l}\text { Cumulative per capita investment in } \\
\text { fixed assets }\left(\mathrm{X}_{14}\right)\end{array}$ & 0.213 & -0.427 & 0.251 \\
\hline
\end{tabular}

\section{Discussion and Conclusions}

The article analyzed the economic resilience of RBCs in Northeast China in terms of resistance and recoverability dimensions during the last two recessionary periods, and analyzed the main attributes of resilience. There are three key findings. First, the general level of economic resilience among the RBCs was low, especially in terms of resistance. Furthermore, different types of cities have responded differently to the recessionary shocks and the subsequent recovery periods. Second, the influential factors that affect economic resilience vary across different economic cycles. Third, location advantage, $\mathrm{R}$ and $\mathrm{D}$ intensity, foreign trade dependence ratio, and supporting policies had positive effects on resilience during both economic cycles, whereas the proportion of employees in resource industries had a negative effect. These points are further elaborated below.

\subsection{Economic Resilience Characteristics of RBCs}

In general, the results showed that the RBCs in Northeast China had low resistance during both recessions, meaning that their growth rate declined more rapidly than the national average. However, during the first economic cycle they also recovered faster because of the negative correlation between resistance and recoverability. Consistent with our results, Li et al. and Su et al. found that the economies of mining cities are vulnerable to external shocks, especially the resource-exhausted mining cities $[44,45]$. Furthermore, Li et al. suggested that the economic vulnerability of coal cities is the lowest, which is consistent with our results, which show that the resistance of coal and forestry 
cities was the lowest during both economic cycles, whereas metal and petroleum cities fared much better [44]. Therefore, increasing the economic resilience of RBCs has become a key task for revitalizing old industrial bases in Northeast China.

\subsection{Attributes of Resilience Vary across Different Economic Cycles}

The influential factors that affect the economic resilience varied across the two economic cycles. This finding supports the view that local responses to economic shocks are far from constant across cycles but, instead, vary according to the specific origins and characteristics of each recession [36]. Nevertheless, location advantage, $R$ and $D$ intensity, foreign trade dependence ratio, and supporting policies had positive effects on resilience during both economic cycles, which suggests that the government should focus on these factors as a way to build up the resilience of RBCs. These findings have profound implications for regional planning. First, to improve location advantage, the government should strengthen transportation infrastructure, and strengthen ties with the central city. This is especially important for forestry-based cities and coal-based cities in Heilongjiang province. Second, the government should increase expenditure on $\mathrm{R}$ and $\mathrm{D}$ activities and improve innovation capacity. Third, more policies and provide financial support to guide and promote the development of RBCs, upgrading industrial structures and fostering non-extractive industries were needed. Furthermore, we found that the proportion of employees in resource industries always had a negative effect on economic resilience; therefore, accelerating the industrial transformation and reducing the proportion of resource-based industries is key to increasing the economic resilience of RBCs. Interestingly, our results also show that the effect of industrial specialization on resilience is not significant and ambiguous: it had a negative impact on resistance during the first recession and a positive impact on resistance during the second recession. This finding is not consistent with the view that regions with diverse economies tend to be more resilient than those with a narrow economic base $[13,27,46]$.

\subsection{Industry Structure and Economic Resilience}

The resistance and recoverability of the secondary industry were significantly higher than that of the tertiary industry during the first economic cycle, but the tertiary industry outperformed the secondary industry during the second economic cycle. This result agrees with the argument put forward by Martin et al. that the role of industrial structure in determining regional resilience changes from one recession-recovery cycle to the next [13]. The reason behind this shift in roles may be two-fold. First, the nature of the two financial crises is not the same. The Asian financial crisis was largely a regional crisis, with limited impact on the developed markets in Europe and the United States, which were the key consumers of industrial products made in Northeast China [47]. On the other hand, the global financial crisis severely affected global markets which put a dent in China's exports and, consequently, negatively impacted the Northeast's secondary industries [48]. Second, from a regional economic perspective, the 10 years that passed between the first and second crises saw a gradual decline in the industrial sectors in the Northeast, both because of dwindling resources and government policy to dismantle uncompetitive state-owned enterprises [49]. At the same time, the tertiary sector in the region continued to grow due to rising income levels and government policy to stimulate domestic consumption. Consequently, when the global financial crisis arrived, the resilience of the tertiary sector was higher than that of the secondary sector.

\subsection{Global Price, Resource Supply, and Economic Resilience}

The global prices of resources have strong impacts on economic resilience. Affected by the 2008 global financial crisis, the price of coal slumped. The Australian coal price fell from 127.1 USD/ton in 2008 to $70.1 \mathrm{USD} /$ ton in 2014. Consequently, the economic recession of coal cities in China was the worst after 2008, and the average value of resistance of coal cities was the lowest among all RBCs. Average annual resource supply also affects the economy and resilience of RBCs. Take Baishan, 
a forestry-coal city, as an example. The Natural Forest Protection Project, initiated in 2000 by the central government, places serious restrictions on the harvesting of natural forests. Furthermore, due to the reducing excessive capacity plan, many small coal mines in Baishan were shut down. Consequently, the timber production in Baishan dropped sharply from 800,000 cubic meters in 2011 to 234,000 cubic meters in 2016 and raw coal production dropped from 16.882 million tons in 2011 to 1.132 million tons in 2016. As a result, the revenue of the coal and forestry industries declined sharply, and economic growth remained at a low level. All of these factors contribute to the near-bottom ranking of Baishan's economic resistance.

Acknowledgments: This work was supported by the National Natural Science Foundation of China (41571152, 41671123, 41771179); the Key Research Program of the Chinese Academy of Sciences (KSZD-EW-Z-021-03); and the Key Consulting Program of the Chinese Academy of Sciences (Y02015005).

Author Contributions: All of the authors made contributions to the work in this paper. Juntao Tan and Pingyu Zhang designed the research. Juntao Tan wrote the paper articles and Pingyu Zhang checked it. Kevin Lo and Fangdao Qiu modified the article and improved language. Jing Li and Wenxin Liu contributed data collecting and results analysis.

Conflicts of Interest: The authors declare no conflict of interest.

\section{References}

1. Sabatino, M. Economic crisis and resilience: Resilient capacity and competitiveness of the enterprises. J. Bus. Res. 2016, 69, 1924-1927. [CrossRef]

2. Folke, C. Resilience: The emergence of a perspective for social-ecological systems analyses. Glob. Environ. Chang. 2006, 16, 253-267. [CrossRef]

3. Xu, L.; Marinova, D.; Guo, X. Resilience thinking: A renewed system approach for sustainability science. Sustain. Sci. 2015, 10, 123-138. [CrossRef]

4. Christopherson, S.; Michie, J.; Tyler, P. Regional resilience: Theoretical and empirical perspectives. Camb. J. Reg. Econ. Soc. 2010, 3, 3-10. [CrossRef]

5. Balsas, C.J.L. Downtown resilience: A review of recent (re)developments in Tempe, Arizona. Cities 2014, 36, 158-169. [CrossRef]

6. Weichselgartner, J.; Kelman, I. Geographies of resilience Challenges and opportunities of a descriptive concept. Prog. Hum. Geogr. 2015, 39, 249-267. [CrossRef]

7. Martin, R. Regional economic resilience, hysteresis and recessionary shocks. J. Econ. Geogr. 2012, 12, 1-32. [CrossRef]

8. Gallopín, G.C. Linkages between vulnerability, resilience, and adaptive capacity. Glob. Environ. Chang. 2006, 16, 293-303. [CrossRef]

9. Simmie, J.; Martin, R. The economic resilience of regions: Towards an evolutionary approach. Camb. J. Reg. Econ. Soc. 2010, 3, 27-43. [CrossRef]

10. Eraydin, A. Attributes and characteristics of regional resilience: Defining and measuring the resilience of Turkish regions. Reg. Stud. 2016, 50, 600-614. [CrossRef]

11. Davoudi, S. Resilience: A bridging concept or a dead end? Plan. Theory Pract. 2012, 13, 299-307. [CrossRef]

12. Hassink, R. Regional resilience: A promising concept to explain differences in regional economic adaptability? Camb. J. Reg. Econ. Soc. 2010, 3, 45-58. [CrossRef]

13. Martin, R.; Sunley, P.; Gardiner, B.; Tyler, P. How regions react to recessions: Resilience and the role of economic structure. Reg. Stud. 2016, 50, 561-585. [CrossRef]

14. Di Caro, P. Recessions, recoveries and regional resilience: Evidence on Italy. Camb. J. Reg. Econ. Soc. 2015, 8, 273-291. [CrossRef]

15. Sensier, M.; Artis, M. The resilience of employment in Wales: Through recession and into recovery. Reg. Stud. 2016, 50, 586-599. [CrossRef]

16. Pendall, R.; Foster, K.A.; Cowell, M. Resilience and regions: Building understanding of the metaphor. Camb. J. Reg. Econ. Soc. 2010, 3, 71-84. [CrossRef]

17. Fingleton, B.; Garretsen, H.; Martin, R. Recessionary shocks and regional employment: Evidence on the resilience of UK regions. J. Reg. Sci. 2012, 52, 109-133. [CrossRef] 
18. Cellini, R.; Torrisi, G. Regional resilience in Italy: A very long-run analysis. Reg. Stud. 2014, 48, $1779-1796$. [CrossRef]

19. Davies, S. Regional resilience in the 2008-2010 downturn: Comparative evidence from European countries. Camb. J. Reg. Econ. Soc. 2011, 4, 369-382. [CrossRef]

20. Courvisanos, J.; Jain, A.K.; Mardaneh, K. Economic resilience of regions under crises: A study of the Australian economy. Reg. Stud. 2016, 50, 629-643. [CrossRef]

21. Dubé, J.; PolèSe, M. Resilience revisited: Assessing the impact of the 2007-2009 recession on 83 Canadian regions with accompanying thoughts on an elusive concept. Reg. Stud. 2016, 50, 615-628. [CrossRef]

22. Doran, J.; Fingleton, B. Employment resilience in Europe and the 2008 economic crisis: Insights from micro-level data. Reg. Stud. 2016, 50, 644-656. [CrossRef]

23. Tan, J.; Zhang, P.; Lo, K.; Li, J.; Liu, S. Conceptualizing and measuring economic resilience of resource-based cities: Case study of Northeast China. Chin. Geogr. Sci. 2017, 27, 471-481. [CrossRef]

24. Hu, X.; Hassink, R. Exploring adaptation and adaptability in uneven economic resilience: A tale of two Chinese mining regions. Camb. J. Reg. Econ. Soc. 2017, 10, 527-541. [CrossRef]

25. Hu, X. State-led path creation in China's rustbelt: The case of Fuxin. Reg. Stud. Reg. Sci. 2014, 1, $294-300$. [CrossRef]

26. Desrochers, P.; Leppälä, S. Opening up the 'Jacobs Spillovers' black box: Local diversity, creativity and the processes underlying new combinations. J. Econ. Geogr. 2011, 11, 843-863. [CrossRef]

27. Davies, A.; Tonts, M. Economic diversity and regional socioeconomic performance: An empirical analysis of the Western Australian grain belt. Geogr. Res. 2010, 48, 223-234. [CrossRef]

28. Boschma, R. Towards an evolutionary perspective on regional resilience. Reg. Stud. 2015, 49, 733-751. [CrossRef]

29. Li, H.; Long, R.; Chen, H. Economic transition policies in Chinese resource-based cities: An overview of government efforts. Energy Policy 2013, 55, 251-260. [CrossRef]

30. Gong, H.; Hassink, R. Regional resilience: The critique revisited. In Creating Resilient Economies: Entrepreneurship, Growth and Development in Uncertain Times; Tim, V., Nick, W., Eds.; Edward Elgar: Cheltenham Glos, UK, 2016.

31. Evenhuis, E. New directions in researching regional economic resilience and adaptation. Geogr. Compass 2017, e12333. [CrossRef]

32. Bristow, G.; Healy, A. Regional resilience: An agency perspective. Reg. Stud. 2014, 48, 923-935. [CrossRef]

33. Huang, Z. Study on China's Economic Cycle and Macro-Control Efforts in 30 Years of Reform and Opening-up. J. Financ. Econ. 2008, 34, 88-100.

34. $\mathrm{Yu}, \mathrm{H}$. The ascendency of state-owned enterprises in China: Development, controversy and problems. J. Contemp. China 2014, 23, 161-182. [CrossRef]

35. Holz, C.A. The quality of China's GDP statistics. China Econ. Rev. 2014, 30, 309-338. [CrossRef]

36. Martin, R.; Sunley, P.; Tyler, P. Local growth evolutions: Recession, resilience and recovery. Camb. J. Reg. Econ. Soc. 2015, 8, 141-148. [CrossRef]

37. Lagravinese, R. Economic crisis and rising gaps North-South: Evidence from the Italian regions. Camb. J. Reg. Econ. Soc. 2015, 8, 331-342. [CrossRef]

38. Pike, A.; Marlow, D.; McCarthy, A.; O’Brien, P.; Tomaney, J. Local institutions and local economic development: The Local Enterprise Partnerships in England, 2010-. Camb. J. Reg. Econ. Soc. 2015, 8, 185-204. [CrossRef]

39. Brakman, S.; Garretsen, H.; van Marrewijk, C. Regional resilience across Europe: On urbanization and the initial impact of the Great Recession. Camb. J. Reg. Econ. Soc. 2015, 8, 225-240. [CrossRef]

40. Mason, C.; Brown, R.; Hart, M.; Anyadike-Danes, M. High growth firms, jobs and peripheral regions: The case of Scotland. Camb. J. Reg. Econ. Soc. 2015, 343-358. [CrossRef]

41. Wang, J.F.; Li, X.H.; Christakos, G.; Liao, Y.L.; Zhang, T.; Gu, X.; Zheng, X.Y. Geographical detectors-based health risk assessment and its application in the neural tube defects study of the Heshun Region, China. Int. J. Geogr. Inf. Sci. 2010, 24, 107-127. [CrossRef]

42. Hu, Y.; Wang, J.; Li, X.; Ren, D.; Zhu, J. Geographical detector-based risk assessment of the under-five mortality in the 2008 Wenchuan earthquake, China. PLoS ONE 2011, 6, 1-8. [CrossRef] [PubMed]

43. Ding, Y.; Cai, J.; Ren, Z.; Yang, Z. Spatial disparities of economic growth rate of China's National-level ETDZs and their determinants based on geographical detector analysis. Prog. Geogr. 2014, 33, 657-666. 
44. Li, H.; Zhang, P.; Cheng, Y. Economic vulnerability of mining city-A case study of Fuxin City, Liaoning Province, China. Chin. Geogr. Sci. 2009, 19, 211-218. [CrossRef]

45. Su, F.; Zhang, P.; Li, H. Vulnerability assessment of coal-mining cities' economic systems in China. Geogr. Res. 2008, 27, 907-916.

46. Duranton, G.; Puga, D. Diversity and specialisation in cities: Why, where and when does it matter? Urban Stud. 2000, 37, 533-555. [CrossRef]

47. Bridges, B. Europe and the Asian financial crisis: Coping with contagion. Asian Surv. 1999, 39, $456-467$. [CrossRef]

48. Chan, KW. The global financial crisis and migrant workers in China: 'There is no future as a labourer; returning to the village has no meaning'. Int. J. Urban Reg. Res. 2010, 34, 659-677. [CrossRef]

49. Li, H.; Lo, K.; Wang, M. Economic transformation of mining cities in transition economies: Lessons from Daqing, Northeast China. Int. Dev. Plan. Rev. 2015, 37, 311-328. [CrossRef]

(C) 2017 by the authors. Licensee MDPI, Basel, Switzerland. This article is an open access article distributed under the terms and conditions of the Creative Commons Attribution (CC BY) license (http:/ / creativecommons.org/licenses/by/4.0/). 